\title{
Human uniqueness on the brink of a new axial age: From separation to reintegration of humans and nature
}

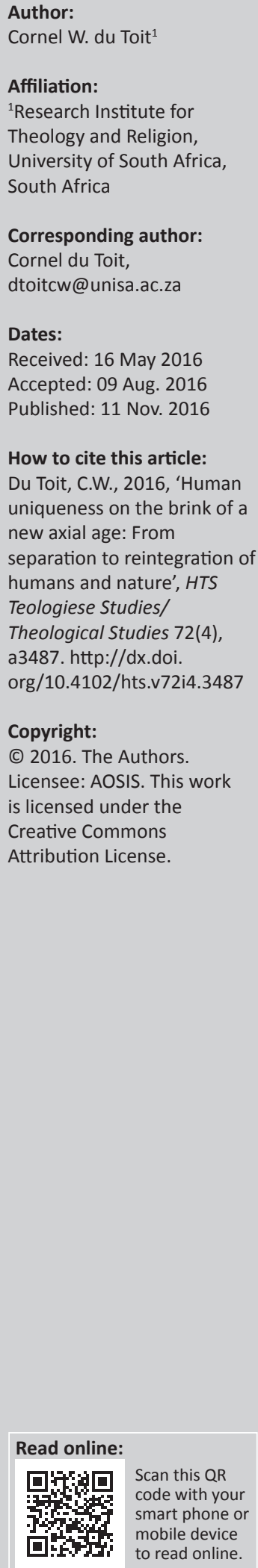

Karl Jaspers' Axial Age concept is used to depict the way humans interact with their environment. The first Axial Age (800-200 BC) can be typified among others as the age in which humans started to objectify nature. Nature was dispossessed of spirits, gods and vital forces that humans previously feared and used as explanation for the origin of things. Secularised and objectified nature became a source of wealth for humans to use and abuse as they like. This has peaked in the post-industrial era which also introduced the Second Axial Age in which we presently live. The Second Axial Age can be typified by a new approach to nature mediated among others by insights from the side of the natural sciences, especially developments in cosmology, our understanding of the quantum world and new insights into the nature of consciousness. Another development in the Second Axial Age is the emergence of the nonhuman turn, new materialism, panpsychism, the notion of the post-human and theological concepts like the 'entangled God'. These developments are discussed with reference to leading thinkers. The nonhuman turn is welcomed as it introduces respect for nature which may contribute to the survival of our planet.

\section{Introduction}

\section{The Axial Age idea}

With advancements in physics especially particle physics and new cosmology; developments in biological sciences, especially studies on mind and consciousness; studies on animal consciousness and advancements in computer technology, scientists and philosophers came to realise that there is more to reality than what is presented in modernism. On the level of consciousness studies researchers acknowledge their limited understanding. Consciousness as a phenomenon cannot be restricted to human consciousness and this opens up the possibility of alternate forms of consciousness that characterise nonhuman species as well as some aspects of the physical world. This development is so revolutionary that it can metaphorically be seen as a new Axial Age. The aim of this article is to unpack these new developments.

The Axial Age refers to the period between 800 and 200 BCE when significant changes took place independently in several ancient civilisations. The current world religions (Buddhism, Hinduism, Daoism, Judaism, Christianity and Islam) can all trace their origins back to the First Axial Age (500 to $300 \mathrm{BCE}$ ). This period delivered great thinkers like Socrates, Pythagoras, Buddha, Mahavira, Confucius, Lao Tse, the Hebrew prophets and so on.

The idea of an Axial Age is not similar to a paradigm shift in science or of changes in world view. It is much broader, affecting the way humans see their world, interact with it and conduct themselves. The Axial Age metaphor's popularity may be due to the optimistic notion of human progress. " Axial breakthroughs" could be understood as shifts to higher levels of reflexivity, with particular emphasis on clearer awareness of human agency, historicity and responsibility' (Arnason, Eisenstadt \& Wittrock 2005:8). Wagner (2005:93) filters out two questions from the Axial Age debate: the first concerns the ways in which human beings relate reflexively to their being in the world and the second their critical interaction with their history in such a way as to give them new orientations in the present. To this he adds the insight to know to what extent being a member of a specific society or civilisation offers opportunities or imposes constraints from the past.

The Axial Age (Achsenzeit) is characterised by a new kind of self-consciousness and reflection that came to the fore in China, Iran, Palestine, India and Greece (Jaspers 1953:2; Wittrock 2005:62). Through this reflection (and renewed self-consciousness) all fundamental categories within which we still think today were formed. Jaspers (1953:194) formulates as follows: 'Rational thinking developed and, in conjunction with it, discussion, in which one throws the ball to the other and a 
perennially creative growth and deepening of consciousness takes place through generations. To every position there was the counter-position. On the whole, everything remained open: insecurity became conscious. An unparalleled disquiet took possession of man. The world seemed to consciousness to be growing more and more chaotic'.

The first aspect that Jaspers (1953:2-3) singles out and which will form the focus of this contribution is that it marks the end of the Mythical Age. 'The Greek, Indian, and Chinese philosophers were unmythical in their insight, as were the prophets in their ideas of God. Rationality and rationally clarified experience launched a struggle against the myth (logos against mythos)'. Jaspers (1953:81-82) identifies three steps in human cognition: 'First, rationalisation in general, which in some form or other is common to all mankind, made its appearance as soon as man as such appeared, and in the guise of "pre-scientific science," rationalised myths and magic; second, science that became logically and methodologically conscious, Greek science, of which there were rudimentary parallels in China and India; third modern science, which has developed since the end of the Middle Ages, became decisive since the seventeenth century' ${ }^{1}$

Jaspers (1953:91-93) traces the birth of modern science back to Biblical religion. The Biblical ethos of veracity at all cost, the belief that the world is God's creation and the idea that God demands knowledge all contributed to the development of a scientific ethos. The idea of creation, says Jaspers (1953:92), makes the created thing worth of love as the work of God, and thereby makes possible 'a hitherto closeness to reality', but it also implied a certain distanciation from reality for it was 'only created Being not Being itself, not God' (ibid).

The Greek cosmologists answered the question about creation differently. They no longer looked for a Creator to explain things but sought to find it in reality itself, reality right before one's eyes. They no longer looked for the origin of being in myths, religion or superstitious ideas but focused on the natural world as to explain the origin of all things. Anaximander (611-547 BCE), for example, explained the origin of the world in formless primeval matter. In the beginning, the world was fluid, and its heat and humidity generated low-order living beings, which gradually evolved into organisms by adapting to their environment. Humans evolved from aquatic fish. Anaximenes (588-524 BCE) selected air as source of all things. Air gave rise to everything through rarefaction and condensation. There are an infinite number of worlds. The Pythagoreans identified numbers as the source of proportion, order and harmony in the universe. Numbers are the basis on which all things depend (a hallmark of science is measurement based on numbers). According to them, the earth revolved around a central fire (not yet the sun, but close enough!).

1.In spite of the reat spiritual achievements from 1500 to 1800 (one can think Miche Bach, Mozart) Jaspers (1953:75-76) does not see this as a Second Axial Age, simply Bach, Mozart) Jaspers (1953:75-76) does not see this as a Second Axial Age simply because Western culture inherited a wealth of experiences and meaning and need not start de novo. This means that there can never be a Second Axial Age because the older cultures get, the more experience and knowledge there are to fall back upon.
A feature of early cosmological thought is that the cosmologists' empirical (sensory) focus inescapably included non-empirical, metaphysical realities. This introduced the beginning of the symbiotic relation between matter and consciousness. Parmenides (from the Eleatic school) is the cardinal example. He distinguishes between sense and reason. The senses offer us the phenomenal world which is the world of appearances. Only reason can apprehend true being. That is a basic principle of idealism: truth is knowable in the domain of reason, not in the sensory sphere. Parmenides, the father of idealism, was a materialist as well: being, supreme reality, occupies space and is finite. What occupies space is matter. This is relevant because it is futile to contrast idealism and materialism. Just as humans are not only bodies or only minds, so science without (metaphysical) ideas or religion without physical reality is not possible (see Berger 1993:34ff). That is the basis of the challenge to accommodate both matter and consciousness in our take on reality. 'Matter' and 'consciousness' represent in a sense realism and idealism. ${ }^{2}$ The tenor of this article endeavours to integrate the two. Realism makes scepticism intelligible (Nagel 1986:90). Realism is sceptical because it holds that our grasp of the world is limited: the world may be inconceivable to our minds. Idealism holds that what there is, is what we can think about or conceive of and that this is necessarily true because the idea of something that we could not think about or conceive of makes no sense (Nagel 1986:90-91). Instead of opposing the two approaches to reality, the interdependence of materialism and idealism must be investigated. It is not so clear anymore where the dividing line between the two approaches lies.

\section{A new Axial Age based on the integration of mind (consciousness) and matter (world)}

As seen above, the development of science depended on a specific view of matter. Humans, as the crown of creation, stood as thinking subjects over objectified dead matter. Nature and its yields were there for the taking.

Mythical thinking introduced transcendent agents as actor(s) in the world. These agents operated in and through matter. Spirits (transcendent agents) manifested themselves in forests, rivers, animals, the weather and so on. Once matter was freed from transcendent powers incarnated in it, it lost its threatening character, became open for investigation and available for human use. This important process which can be linked to the First Axial Age was the secularisation of matter (nature).

Although the belief in animated matter came intuitively for our ancestors, the nature and role of transcendent powers

2.This is a false dichotomy. To deny matter in a Gnostic way is not helping us forward The future of humanity and of this planet depends on a new appreciation of matter. The materialism-idealism divide must be overcome. I differ from Gregersen's (2010:321) view that "Matter as such has been demoted from its central role, to be replaced by concepts such as organization, complexity and information". These concepts make no sense without the presence of matter. They stress their integration with matter. 
were formulated by philosophies and religions as societies progressed. Bondarenko (2011:114) expresses it as follows: '...it goes without saying that religion as belief in supernatural in all forms has been determining the picture of the universe including the place of society and the individual in it, the meaning and goal of life, the mode of behaviour in humans' minds for thousands and thousands of years'. The present change in the state of religions has direct bearing to the transition to the Second Axial Age (ibid). This 'state' refers to secularisation. Democratic civil society as we know it today would not have been possible without this process which Bondarenko (2011:115) calls the 'atheisation' of society that was determined through events like the Reformation, Enlightenment, religious wars, bourgeois revolutions, the Industrial Revolution, rapid development of technology and science, and so on. This process gradually shifted the focus away from transcendent ideals, a kind of civic religion concerned with human well-being on earth, focused on immanent, terrestrial concerns and developing a nontranscendental ethics. It took European consciousness 300 years (from the mid-15th to the mid-18th centuries) to pass through several stages to attain a non-religious but 'scientific' worldview, marking the end of the First Axial Age (AAI) (Bondarenko 2011:118). While First Axial Age cultures were inspired by religions, cultures of the Second Axial Age (AAII) are marked by religious decline which Bondarenko (2011:117-118) attributes to the traumatic influence of the two world wars. ${ }^{3}$

Today we have come to realise how integrated we are with matter - genetically, technologically and even religiously (deep incarnation). We now realise how we depend on matter and that it holds the secret to our continued material existence of a flourishing life (medicine and good health).

Our time is considered by some (see Bondarenko, Kurzweil) as the beginning of the New (Second) Axial Age. Terms like singularity, trans-humanism and nonhuman turn are used to describe the optimism related to techno-scientific developments that may shift the human race to a new level of existence. Several factors contributed to this development: advances in particle physics and new cosmological insight, developments in cognitive and brain sciences, consciousness studies and medical advances (gene technology), to mention a few. On top of this, new ecological awareness brought to the fore a new appreciation for matter (nature, our planet) as well as an increased sense of responsibility.

New ways of thinking emerged: eco-theology, deep incarnation, panpsychism and the notion of the 'entangled' God, to name a few. These developments mark a transformative shift in consciousness that may put humanity on a new course of interactions with matter. Our future as well as human flourishing depends on the way we see, know and interact with matter in all its various forms. 3.Bondarenko (2011:123) mentions that in the post-war (Wwii) situation of spiritual
and economic ruin and confusion Jaspers was seeking universal values that once had made history global and could integrate the world of his time.
Perhaps Jaspers sensed that something totally new was to be born from technological developments. He saw technological advances as the ultimate revolution since recorded history.

The technological age, in which we have been living for a bare century and a half, has only achieved full dominion during the last few decades; this dominion is now being intensified to a degree whose limits cannot be foreseen. We are, as yet, only partially aware of the prodigious consequences. New foundations for the whole of existence have now been inescapably laid. (Jaspers 1953:61)

Cousins (1994) also referred to a second axial age that started to materialise towards the end of the 20th century, characterised by the focus on the global rather than local identity, high stakes placed on ecological responsibility and the fate of our planet. The little resources left must be preserved; the continued invasion of nature must be halted; the extermination of species must be curtailed. This new self-consciousness is also open to the reality of the spiritual dimension, to the sanctity of life.

The combination of spirituality and materiality can be read in the so-called nonhuman turn, in trans-humanism, deep ecology, eco-theology, animal studies and animal consciousness, and new versions of panentheism.

\section{The history of man and matter}

The Greek interpretation of matter held sway until the 17th century when the concept of matter was reformulated in the philosophy of materialism. Matter was replaced by the Newtonian concept of mass. The third reformulation of matter came in the 20th century under influence of relativity, quantum mechanics and expanding universe cosmology (McMullin 2010:13). Some highlights in the history of matter will be dealt briefly.

The very rich history of humans' view on and interaction with matter can be interpreted from many angles of which the dualist approach is perhaps the most dominant. The dualist approach to matter is analogical to the following dualisms: matter-form dualism (Aristotle), res extensa - res cogitans dualism (Descartes), mind-body dualism, mindbrains dualism and organic-inorganic dualism.

Matter was never simply seen as matter but linked with some non-substantialist concept like form, idea, consciousness, energy, spirit, etc. It was imbued with spirit in animism, and various forms of vitalism, understood in terms of idea (Plato), form (Aristotle), spirit (Leibniz, Hegel), consciousness (panpsychism) and so on.

Matter (Greek hyle $)$ is the most basic, sensuous, tangible stuff that we know. It not only surrounds us, we ourselves are made up of it. We are thinking matter surrounded by other forms of thinking matter. Matter is the original answer to the ontological question, to the arche question. But matter 4. Hule means literally 'wood" and was adopted by Aristotle to signify matter because there was no common word for matter. 
changes in form and substance indicating that something more basic should be at the basis of all. The Greek cosmologist already proposed not only material stuff (e.g. Empedocles's four elements) as candidate but also immaterial reason (logos) as Parmenides did. This implies that material stuff originates from immaterial stuff (and in line with the panpsychic idea of consciousness as underlying principle). The arche question however brought new questions to the fore. Matter changes. What is the primal principle? ${ }^{5}$ Plato sought the answer in the doctrine of the Forms. What is ultimately real is eidos: the idea of a thing (Clayton 2010:40). Ideas are real, matter an illusion.

Aristotle departed from the idea that matter is an illusion. What differentiates one thing from another is its form. Pure matter is undifferentiated stuff, that which lies beneath (Lat. subjectum) and which takes on the properties of a thing without itself having any properties. It acts as container (khôra) $^{6}$ (Clayton 2010:42). 'Matter is that unknown which, when combined with form, produces this or that specific object. But taken by itself it is completely unknown, mysterious' (ibid 43).

\section{The dematerialisation of matter (reality)}

The dematerialisation of nature began with Newton whose theory of gravity was related to the seemingly occult notion of 'action at a distance'. There was no intervening matter between large bodies like the sun and the earth to explain gravity. 'If Newton dematerialized nature on the largest of scales, from the solar system up, modern physics has done the same on the smallest of scales, from the atom down' (Holt 2012:186-187).

In the development of Newton's thought, matter increasingly occupied a smaller part of his universe. Light could travel through transparent material only because there were fewer particles (material corpuscles) present (McMullin 2010:21). It was Samuel Clarke, follower of Newton, who stressed that space was predominantly filled by immaterial forces. Matter was the 'most inconsiderate part' of the universe (McMullin 2010:21).

According to Jolley (quoted in Clayton 2010:47), Leibniz (a contemporary of Newton) reduced matter to a merely epiphenomenal property of the monads. Leibniz referred to bodies as 'sets of harmonized perceptions'.

According to Faraday, physical reality actually consists not of matter but of fields (Holt 2012:187). Bernard d'Espagnat also argued that it is not accurate to see objects as objects because they are rather properties of a field (see Clayton 2010:55).

5.Similar to the God-question the matter-question also sought one primal principle that could explain all existence.

6.The chora (from Plato's Timaeus) represents a third realm beyond being (world of 'morms, the model) and becoming (the copy). It is the space of generation, the

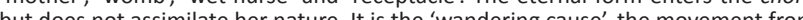
but does not assimilate her nature It is the 'wandering cause', the movement from potentiality to actuality that operates in the interstices between objects. The chor enables and distorts the autopoiesis of apparently incorporeal matters like though (see Sheldon 2015:211-214)
Clayton (2010:54) mentions that with Röntgen's discovery of the phenomenon of radioactivity, in which solid objects gradually convert themselves into radioactive waves, physicists recognised that there is no fundamental ontological difference between matter and energy as was expressed in Einstein's $E=\mathrm{mc}^{2}$. This implies that rest mass can be transformed into radiation and vice versa. Conversely, energy can be transformed into mass in the process of pair creation when the energy available is high enough to transform into the rest of masses of the two particles (McMullin 2010:23). Then came Schrödinger's wave equation and the waveparticle duality. According to Stapp (2010:112), the collapse of the wave function suggested that the observer was constitutive in determining the physical world. The original Copenhagen interpretation of quantum theory eschewed ontology and avoided all commitments about what really exists. Heisenberg saw reality as built out of psychological events and not out of matter. The focus is on objective tendencies for events to occur and the transition from the 'possible' to the 'actual' takes place during the act of observation (Stapp 2010:113).

On the level of particle physics, the role of 'nothingness' came to the fore. Every particle has an anti-particle and the two will collapse each other; there is almost an equal amount of matter and anti-matter; when quantum level particles pop into existence spontaneously. Mathematician Sir Roger Penrose and cosmologist Max Tegmark saw reality as mathematical in essence. Mathematics is the science of structure. It is uninterested in matter (stuff). Thus Holt (2012:189) deduces that if the universe is structure all the way down, then it is characterised by mathematics. Holt (2012) sketches the following scenario of a zero-energy universe:

Suppose the total energy of the universe is indeed exactly zero. Then, owing to the trade-off in uncertainty between energy and time (as decreed by the Heisenberg principle), the indeterminacy in its time span becomes infinite. In other words, such a universe, once it popped into existence out of the void, could run away with itself and last forever. It would be like a loan of pure being that need never be repaid. (p. 142)

No 'primary matter' serves as the basic stuff out of which all else is composed. Instead the deeper one pursues the explanations, the more nonmateriality reveals itself in (or behind) the solid objects around us. (Clayton 2010:58)

All of this may suggest that materialism is an illusion. But this is not accurate. Clayton's suggestion is perhaps more accurate: 'Relativity theory in cosmology and the complementarity thesis in quantum physics suggest that the basic reality is some sort of hybrid "matter-energy"' (ibid 57). Along the same lines, McMullin (2010:25, 34) states that if matter is to be retained there are two alternatives open. Matter must be broadened to include mass-energy, or it could be restricted to rest mass which leaves the world with two constituents: matter and energy.

\section{New materialism}

The 21st century has seen challenges to the centrality of epistemology in literary and cultural theory and the revival 
of neuroaesthetics, phenomenology and affect theory. This goes along with a newly emergent realism in the humanities which especially manifested in speculative realism, objectoriented ontology, new realism and feminist new realism (Sheldon 2015:193).

But what is philosophical materialism? Bennett (2015:223) interprets its manifestation in the West as the view where '... fleshy, vegetal, mineral materials are encountered not as passive stuff awaiting animation by human of divine power, but as lively forces at work around and within us'. The nonhuman or inorganic matter is 'influencing' us, 'appealing' to us and we need to find a new vocabulary to express the '... participation of nonhumans in "our" world' (Bennett 2015:225)

Science has introduced at least three aspects of matter: its stuff or particle character (molecules, atoms, quarks, quantum particles); matter as energy (kinetic potential) and the information content of matter (ability to form patterns) (see Clayton 2010:321; McMullin 2010:34). New insight in these fields occurs all the time. What concerns us is the way that matter in new ways affects our worldview, our self-image and the way human biology and matter may be integrated in a trans-human existence.

New materialism represents the 'nonhuman' turn. The reintegration of humans with nature or matter cannot be separated from new developments in consciousness studies and the so-called nonhuman turn with renewed interest in the nature of matter. It is interpreted by Bennett (2015) as follows:

The nonhuman turn, then, can be understood as a continuation of earlier attempts to depict a world populated not by active subjects and passive objects but by lively and essentially interactive materials, by bodies human and nonhuman. (p. 224)

Sheldon (2015) indicated that the nonhuman as umbrella term calls attention to the myriad ecological, biological, and physical processes that:

have no truck with human epistemological categories whatsoever. The majority of Earth's living inhabitants are nonhuman ... and nonhuman characterises the deep nonliving recesses of the Earth, the biosphere and space's vast expanse. (p. 195)

Humans stand in relationship with matter. They are matter themselves - 'thinking matter'. A specific aspect of new realism is feminist new materialism (see Sheldon 2015). It represents a specific critique against object-oriented ontology which postulates a specific anti-relational ontology in which objects recline at a distance from each other and from networks in which they are embedded (Sheldon 2015:194). Feminist new materialism criticises the epistemology of object-oriented ontology as epiphenomenal and limited to human knowers. Humans see according to a set of learned practices and reproduces the world accordingly. This obfuscates the way we represent reality as well, because what representation represent precedes its representation for which language merely presents a label. 'That epistemology and ontology are linked - that what we know sculpts how we act - is our legacy from social construction' (Sheldon 2015:202).

Object-oriented ontology is seen as masculine, modernist, abusive:

It is no mistake ...that woman are caught up in relations of metaphor with the Earth, figured as the exploitable resource of nurturance, with womb as the origin from which manly activity proceeds, with nature as unruly, irrational primitive abundance, and with matter sculpted and stamped by transcendent form (Sheldon 2015:199).

Feminist new materialism proposes instead that ideas and things do not occupy separate ontological orders but instead are co-constituents in the production of the real (Sheldon 2015:196). This reintroduces life somehow into matter in an approach called 'vital materialism' (Sheldon 2015:208) which endeavours to 'dissipate the onto-theological binaries of life/matter; human/animal; will/determination; and organic/inorganic' (ibid). It claims that there is life in the interstices. This need not be life as we know it. It can be an inorganic 'life' that moves 'vigorously through the biological as through the machinic and the ideational' (Sheldon 2015:209).

\section{Physics, metaphysics and the ineffability of 'thingness'}

Matter is evasive and cannot easily be captured by some basic idea or concept. Clayton (2010:50) sees it as an unsolved conundrum, continually declining our grasp, which brings him to ask whether 'matter is in its essence that which cannot be understood, that which inevitably recedes from us as we approach it'.

No 'primary matter' serves as the basic stuff out of which all else is composed. Instead, the deeper one pursues the explanations, the more nonmateriality reveals itself in (or behind) the solid objects around us. (Clayton 2010:58)

Heidegger (1975:163ff) has indicated in his essay Das Ding that the Thing is incalculable and is persistently withdrawing from us. Usually the thing is what is at hand, like a jug. This is what makes up our reality and which we control. But we have to ask deeper questions. 'What in the thing is thingly? What is the thing in itself? We shall not reach the thing in itself until our thinking has first reached the thing as thing' (Heidegger 1975:167-168). When we do think we discover that we cannot 'grasp' a simple thing like a jug. What the potter does with the clay when making a jug is simply to define 'nothingness' by defining it with the jug's bottom and sides. 'Sides and bottom are, to be sure, what is impermeable in the vessel. But what is impermeable is not yet what does the holding... The emptiness, the void, is what does the vessels holding' (Heidegger 1975:169). The void is, however, what escapes our grasp. This becomes metaphor for the elusive nature of the thing, of matter, of reality. 
The 'thingness' of the artwork Heidegger calls Erde. Erde is the earth, matter in its objectivity and self-enclosure. It is only when a meaningful encountering with the artwork takes place that it is transformed from matter in its objective mode (Dinglichkeit) to 'world' (Welt) - that which touches and moves us (Heidegger 1975:15-88). When we are moved we are no longer controlling subject, the mover, but subjected to a transcendent force that moves us.

That world (Welt) emerges from earth (Erde) signifies the dependence of meaning/cognition/creativity on brute matter and the way in which spirit can only manifest itself through a medium (matter). It is only in and through matter that idea/creativity/art/spirit can be manifested. Without incarnation there can be no God, without marble no Pietà.

\section{Matter and relation}

Matter was seen 'was seen by...' La Mettrie and d'Holbach in different forms but they denied the existence of spirit as something that lay outside the scope of mechanical philosophy. Matter was the total opposite of spirit, devoid of life (see McMullin 2010:20). It is counter-intuitive to attribute spirit to dead matter. But doesn't the amount of information present in matter influence its brute 'stuffiness'? Kurzweil (2005:37) has indicated that a kilogram of rock can hold up to $10^{25}$ bits of information. But for all purposes the information is random and of little consequence (for human purposes) because of its lack of complexity. ${ }^{7}$ The idea of complexity requires a minimum amount of meaningful, non-random but unpredictable information to characterise a system or process (ibid). He correctly indicates that increased complexity is not necessarily the aim of evolutionary development but better answers to an organism's challenges in a specific environment. Randomness is the opposite of order and order is information that fits a purpose (ibid 38ff).

The difficulty with any object-oriented ontology is a deeply non-relational concept of the reality of things (Bennett 2015:227). Matter as such or in some objective form has a history of its own, a specific identity. It exerts influence, and can stand in a relationship to other forms of matter or life. Bennett (2015:230) refers to Harman who referred to this relation as 'communication' between objects.

Harman (quoted in Bennett 2015) stresses the withdrawn nature of matter:

'The real problem is not how beings interact in a system: instead, the problem is how they withdraw from that system as independent realities while somehow communicating through the proximity, the touching without touching, that has been termed allusion or allure ...' (p. 232)

Harman is critical of the claim that everything is connected because it distracts attention from the 'non-connections' between objects (their withdrawn nature). This is important

7.Complexity is defined by Murray Gell-Mann as the algorithmic information content (AIC) of a set of information. This is the length of the shortest program that will cause a standard universal computer to print out a string of bits and then stop (quoted in Kurzweil 2005:37). because it opposes the way in which human hubris objectifies, controls, misuses (see Bennett 2015:232).

\section{Kurzweil and the integration of man and matter in the so-called 'singularity'}

Ray Kurzweil is a well-known American futurist and transhumanist. Kurzweil (2005:14-21) distinguishes six epochs of evolution in which matter will progressively be integrated with the human. In each epoch, increased information plays a pivotal role. Epoch one is physics and chemistry where we gain information of atomic structures; epoch two focuses on biology and the information of DNA; epoch three represents the brain and information of neural patterns; epoch four focuses on technology and the information of hardware and software designs; epoch five represents the merger of technology and human intelligence, and this culminates in epoch six where the universe wakes up. Here patterns of matter and energy in the universe become saturated with intelligent processes and knowledge.

The notion of singularity comes from mathematics. Kurzweil (2005:136) set the date for the singularity to appear as 2045. This is when humans will transcend their biology and almost all of human existence will be computerised.

What interests us in his ideas is his view on matter. Biological evolution has developed from systems with essentially no intelligence to the ultimate ability of matter to perform purposeful computation. But biology is slow and has taken us only 'part of the way'. Technological evolution will take us close to the limits (Kurzweil 2005:137).

The connection of brute matter with information, energy and quantum computation has contributed to a totally new appreciation of matter. Kurzweil (2005:131) has the following to say in response to the question 'How smart is a rock?': A kilogram of rock has about $10^{25}$ atoms which are all in motion, exchanging electrons, changing particle spins end generating rapidly moving electromagnetic fields.

Researchers from the University of Oklahoma have succeeded in storing 1024 bits in the magnetic interactions of the protons of a single molecule containing 19 hydrogen atoms. If applied to the kilogram of rock, it means the rock represents at least $10^{27}$ bits of memory (representing a processing capacity of $10^{42}$ ). In spite of all the activity the rock is not performing any useful work because the atoms in the rock are effectively random. In comparison, the human brain has approximately $10^{14}$ interneuronal connections which can store in total about $10^{18}$ bits and has an estimated $10^{27}$ bits of theoretical memory capacity (Kurzweil 2005:137). ${ }^{8}$

The human brain uses analogue and digital methods to do computations. Most of its neurons work at the same time,

8.For John Archibald, Wheeler's idea of it-from-bit can be explained by differences. Science explains how differences in the distribution of mass/energy are associated with differences in the she of a space-time or how differs/ences in the charociated with differences in the shape of a space-time or how differences in the charge of particle is associated with differences in the forces it feels and exerts. States of the universe can thus be seen as pure information. "The world is nothing but flux of pure differences, without any underlying substance. Information ("bit") suffices for existence (“it")' (see Holt 2012:189-190). 
resulting in about one hundred trillion computations being carried out simultaneously. The brain's pattern-finding abilities are based on this (ibid 149). The upshot is that computer technology will soon surpass the brain's abilities and the future of human thinking lies in appending our biology with technology.

\section{Panpsychism}

Panpsychism sees consciousness as typical of all matter whether it has a brain or not. This in a way turns materialism on its head. Materialism in its strictest sense reduces everything to matter. Even mind is a consequence of matter or simply matter in the mode of consciousness. Panpsychism turns this around. Basic to all things that exist is consciousness. Panpsychism endeavours to unite the universe in one grand consciousness. This relates all existence and existing things to each other in some way or another. We owe our existence to the matter formed through cosmic processes. Some feel that the universe 'speaks' to them, enfolds in them and 'receives' them back at the end of their lives. This sentiment comes to the fore in panentheism where our fundamental loneliness is addressed with eternal belonging.

Panpsychism must be read against the metaphysics of consciousness. In panpsychism consciousness enjoys ontological precedence:

Consciousness didn't mysteriously 'emerge' in the universe when certain particles of matter changed to come into the right arrangement; rather, it's been around from the very beginning, because those particles themselves are bits of consciousness. A single ontology thus underlies the subjective information states in our minds and the objective-information states of the physical world-whence Chalmers's slogan: 'Experience is information from the inside; physics is information from the outside.' (see Holt 2012:194ff)

But it is more complex than this. Nagel (1986:50) recaps that we cannot understand how a mental event could be composed of myriad smaller events. 'We lack the concept of a mental part-whole relation' (ibid). Everything 'happening' in the mind at a specific moment seems to be present together to the conscious self. Nagel indicates correctly that the unity of consciousness poses a problem for the theory that mental states are states of something as complex as the brain. 'Panpsychism is just a particular startling manifestation of the problem' (ibid). The many parts of the brain working together to form a feeling of unity can be transposed panpsychically to non-mental entities. The brain is only one example of the difficulty of ascribing mental states to something that also has physical properties:

It is difficult to imagine how a mental unit can have physical parts... The strange truth seems to be that certain complex, biological generated physical systems, of which each of us is an example, have rich nonphysical properties. An integrated theory of reality must account for this, and I believe that if and when it arrives ...it will alter our conception of the universe as radically as anything has to date. (Nagel 1986:51)
To move from human consciousness to animal consciousness and to the forms of awareness that constitute lower organisms constitutes a huge leap. Crossing the border into the territory of lifeless matter brings us in the sphere of the speculative. But we do not consider our existence as speculative and this would not have been possible without lifeless matter.

Panpsychism displays traces of vitalism, personification and anthropopathisms. Panpsychism states that all matter has experience because matter matters, that is, it works, interacts, makes history. This ineluctably implies consciousness. But it makes no sense that dead matter has consciousness, memory or history. The presence of a god, the mind or the memory of God in, and under matter (perichoresis) may make such an option possible. This translates into 'deep incarnation'.

\section{The participatory panpsychism of Kauffman}

A new panpsychist version of the quantum world has just been proposed by Stuart Kauffman (2016:36ff, see also 2015:293-299). Kauffman approaches quantum reality with the distinction between what is possible ${ }^{9}$ (res potentia) and what is actual (res extensa, as real actuals). The possible and the actual give rise to one another via measurement (Kauffman 2016:37). But measurement presupposes mind and should have taken place since the Big Bang long before the appearance of humans. He suggests the possibility of quantum variables that measure one another, perhaps consciously and with free will. 'This will be part of the proposed panpsychism and is, in fact, part of what is called decoherence' (ibid 38). He proposes the triad:

The triad consists in actuals, possibles, and mind measuring possibles, to yield new-in-the-universe actuals. New actuals give rise acausally and instantaneously to new possibles for mind to measure, yielding again new actuals that yield new possibles for mind to measure. Here, nothing is. All is a becoming, all in status nascendi. The role of mind, with consciousness and perhaps free will, is to mediate measurement converting possibles to actuals. Quantum mechanics is about this triad on this view. (ibid 41)

This brings him to a kind of participatory panpsychism. Wherever measurement happens in the universe, via sets of entangled variables, consciousness happens. ${ }^{10}$ In this way mind and matter always interact. 'If free will is involved, then the becoming universe depends upon intent ... We then live in a vastly participatory universe' (ibid 42). This approach underscores the possibility of a cosmic mind.

\footnotetext{
9.Kauffman follows CS Peirce in this regard who argued that actuals and probables do obey the law of excluded middle; possibles do not (Kauffman 2015:295 2016:39). This leads to a new dualism (analogical to the wave-particle dualism). On this dualism, res potentia concerns unmeasured quantum processes (the wave function). Res extensa concerns measured quantum processes (the measured particle).

10.Lloyd (2010:97) mentions that in the 1990s researchers showed just how atoms and elementary particles compute at the most fundamental level. He sees the computin un computing universe not as a metaphor but as a physical fact. the universe is physical system that can be programmed at its most microscopic level to perform universal digital computation (ibid 103). "But we have acomputer - the univers itself, which at its most macroscopic level is busily processing information... quantum mechanics provides the universe with a constant supply of fresh, random bits ...generated by the process of decoherence" (ibid 102).
} 


\section{The 'entangled' God of Wegter-McNelly}

Wegter-McNelly saw in quantum entanglement the possibility of endowing matter with relationship. ${ }^{11}$ He used the concept of quantum entanglement as metaphor for God's relation with creation. 'God's entangled presence underwrites the freedom of creation to be and become itself, even as this presence transformatively brings creation's behavior into accord with God's own activity' (Wegter-McNelly 2011:140). He developed his ideas with reference to McFague and Moltmann (2011:42-45, 133, 136).

Wegter-McNelly endeavours to understand the world theologically from an ecological, evolutionary and nuclear paradigm (ibid 134-135). He sees the Trinity as fundamentally entangled 'within' Godself and freely entangled 'with' creation (ibid 125). The entanglement metaphor enables him to stress God's intertrinitarian relationship (see also perichoresis [ibid 128] as well as God's relationship with creation: 'The world as it exists is not in God but in relationship with God' (ibid 133). God's presence and action in the world is seen by virtue of God's entangled relationship with it (ibid 140).

The examples above serve to indicate a new consciousness of the relatedness of all things on all possible levels. This will undoubtedly also colour our ethics and spirituality in the time to come.

\section{Conclusion}

While the first Axis represents the separation (distanciation) of humans from nature, the second Axis represents the return of humans to nature (matter) and their integration with it (on an elevated techno-scientific, ecological level). Some readings of the First Axial Age include self-distanciation and transcendence as the acquired ability to stand back and look beyond the natural; acquired criticism, the cognitive liberation of humans from embeddedness in nature and its cycles; the transition from mythic to theoretical culture. The human race progressed from unity with nature (hominids) to a mimetic culture, to a mythical culture, culminating in a theoretical culture (material distanciation), as embodied in the First Axial Age which influenced all later developments up to the present.

It remains to be seen if the nonhuman turn merits the claim of introducing a new Axial Age. What seem certain is that the new focus on matter and all its ramifications is more than a passing vogue. Our ecological needs demand a new awareness of environment and all matter contained in it abiotic as well as biotic. Human invasiveness must be curbed

11.The fact that the quantum world seemingly needs some form of observation measurement, conscious interaction, reminds of Berkeley's view of esse est percip. That means that for unthinking things to exist is to be perceived. This represents a kind of idealism which allocates unprecedented importance to humans. I go alon with Nagel's realism that holds that our grasp of the world is limited in respect of what we can know and holds that our grasp of the world is limited in respect of what we can know and conceive (Nagel 1986:90). The idealist notion is that what there is, is what we can think about or conceive. Nagel (ibid 93, 96) supports the position that what there is must be possibly conceivable by us, or something base on some kind of evidence. The notion of something that cannot be thought about by us makes no sense. This means that the existence of unreachable aspects of reality is independent of their conceivability by an actual mind. Nagel (ibid 101) upholds the Kantian idea that how things are in themselves transcends all possible appearances or human conception. in light of the vulnerability of life forms and the future of this planet. Where the First Axial Age contributed to the dedeification of nature, the objectification of the world and the establishment of human supremacy, the Second Axial Age stresses human materiality and the interdependence of man and matter. This also opens trans-human possibilities with all the ethical challenges it entails.

The elevation of and respect for matter can be welcomed and could help in informing our ecological awareness. The renewed understanding of humans as thinking matter is positive as well since it helps us in overcoming mind-body dualisms and may temper human hubris. It contributes to the reinterpretation of transcendent notions of soul and fights forms of new-Gnosticism.

The appreciation of matter and its elevation to the sphere of consciousness, intelligence and information singles matter out as pivotal in determining the future of humans, all other species and this planet. The manipulation of matter in its abiotic and biotic forms will determine the quality of human life and our longevity, as well as our intellectual and other abilities. The new interest in matter repositions humans' place in the universe and stresses holistically our integration in the greater scheme of things.

Kurzweil (2005:387) elevates matter to the spiritual realm: ' ... it is precisely in the world of matter and energy that we encounter transcendence, a principle connotation of what people refer to as spirituality'. He attributes transcendence to all matter and in it makes sense in a metaphorical way of matter as always changing and taking on different forms. It cannot however be compared with the nature of human spirituality as transcendence. Kurzweil (ibid 389) draws matter into the human realm of conscious intelligence. 'But ... the matter and energy in our vicinity will become infused with intelligence, knowledge, creativity, beauty, and emotional intelligence (the ability to love, for example) of our human-machine civilisation'. Kurzweil's ideas can be seen as present-day expression of anthropopathism.

There are other problems as well. Apart from the overoptimism of present in Kurzweil's singularity, it is difficult to imagine the whole cosmos becoming human-like. In a sense this places humanity in the centre of the universe again as it was with the geocentric worldview. But human personhood is linked to human embodiment, human emotion, language and spirituality as it emerges in a web of relationships. The transpose all of this to matter is a metabasis eis allo genos.

Matter cannot be human without becoming human and humanity will be lost if it becomes machine-like. To simply assume a facile combination of the two is science fiction. If we were to evolve into the 'trans-human' we will also become inhuman. It is exactly our biology that developed over millions of years that make us the kind of species we are.

Finally on the level of consciousness many questions arise. I concur with the questions asked by Holt (2012:195): How can 
many consciousnesses combine to form one consciousness? How can many little bits of mind-stuff unite in one megamind? How can we say that electrons and protons are inwardly mental if we do not know how this gets unified into full-blown human consciousness? It remains to be seen to what extent quantum coherence or any other process may contribute to a better understanding of cosmic unity and a cosmic mind.

Humans are unique precisely because they are mortal, live a relative short life which changes all the time, seek for meaning throughout their lives and find it in some form of transcendent relation or other, and depend on love, acceptance and forgiveness to compensate for their loneliness, ignorance and mistakes. Any 'premature' apotheosis will terminate humanity as we know it. We will lose our uniqueness in any machine-like or computed existence which will relegate us to similar replicas of the same single program or idea.

\section{Acknowledgements Competing interests}

The author declares that he has no financial or personal relationships which may have inappropriately influenced him in writing this article.

\section{References}

Arnason, J.P., Eisenstadt, S.N. \& Wittrock, B., 2005, 'General introduction', in J.P. Arnason (ed.), Axial civilizations and world history, pp. 1-14, Leiden, Boston: Brill.

Bennett, J., 2015, 'Systems and things. On vital materialism and object-oriented philosophy', in R. Grusin (ed.), The nonhuman turn, pp. 223-239, University of Minnesota Press, Minneapolis, MN.

Berger, H., 1993, Wat is metafysica? Een studie over transcendentie, Van Gorgum, Assen, Maastricht.

Bondarenko, D.M., 2011, 'The second Axial Age and metamorphoses of religious consciousness in the Christian world', Journal of Globalization Studies 2, 113-136.
Clayton, P., 2010, Unsolved dilemmas: The concept of matter in the history of philosophy and in contemporary physics, in P. Davies \& N.H. Gregersen (eds.), Information and the nature of reality, pp. 38-62, Cambridge University Press, Information an
Cambridge.

Cobb, J.B. \& Griffin, D.R., 1977, Mind in nature, University Press of America, Washington, DC.

Cousins, E., 1994, Christ of the 21st century, Continuum, NY.

Davies, P. \& Gregersen, N.H. (eds.), 2010, Information and the nature of reality, Cambridge University Press, Cambridge.

Dharma-wardana, C., 2013, A physicist view of matter and mind, World Scientific, London.

Gregersen, N.H., 2010, 'God, matter, and information: Towards a Stoicizing Logos Christology', in P. Davies \& N.H. Gregersen (eds.), Information and the nature of reality, pp. 319-348, Cambridge University Press, Cambridge.

Gregersen, N.H. (ed.), 2015, Incarnation, Fortress, Minneapolis, MN.

Heidegger, M., 1975, Poetry, language, thought, Harper \& Row, Toronto.

Holt, J., 2012, Why does the world exist?, Liveright, London.

Jaspers, K., 1953, The origin and goal of history, Yale University Press, New Haven, CT.

Johann, P. (ed.), 2005, Axial civilizations and world history, Brill, Leiden.

Kauffman, S., 2015, 'Natural incarnation: From the possible to the actual', in N.H. Gregersen (ed.), Information and the nature of reality, pp. 289-308, Cambridge University Press, Cambridge.

Kauffman, S., 2016, 'Cosmic mind?', Theology and the Science 14(1), 36-47. http:// dx.doi.org/10.1080/14746700.2015.1122324

Kurzweil, R., 2005, The singularity is near. When humans transcend biology, Penguin, London.

Lloyd, S., 2010, 'The computational universe', in P. Davies \& N.H. Gregersen (eds.), Information and the nature of reality, pp. 92-103, Cambridge University Press, Cambridge.

McMullin, E., 2010, 'From matter to materialism ... and (almost) back', in P. Davies \& N.H. Gregersen (eds.), Information and the nature of reality, pp. 15-37, Cambridge University Press, Cambridge.

Nagel, T., 1986, The view from nowhere, Oxford University Press, Oxford.

Sheldon, R., 2015, 'Form/matter/chora. Object-oriented ontology and feminist newmaterialism', in R. Grusin (ed.), The nonhuman turn, pp. 193-222, University of Minnesota Press, Minneapolis, MN.

Stapp, H., 2010, 'Minds and values in the quantum universe', in P. Davies \& N.H. Gregersen (eds.), Information and the nature of reality, pp. 104-119, Cambridge University Press, Cambridge.

Wagner, P., 2005, 'Palomar's questions. The Axial Age hypothesis, European modernity and historical contingency', in J.P. Arnason (ed.), Axial civilizations and world history, pp. 87-106, Leiden, Boston: Brill.

Wegter-McNelly, K., 2011, The entangled God: Divine relationality and quantum physics, Routledge, New York.

Wittrock, B., 2005, 'The meaning of the Axial Age', in J.P. Arnason (ed.), Axial civilizations and world history, pp. 51-85, Leiden, Boston: Brill. 